\title{
Synergetic Learning Model: The Sum is Greater
}

\author{
$\underline{\text { https://doi.org/10.3991/ijac.v13i1.12255 }}$ \\ Kevin S. Thompson \\ University of Connecticut, Storrs, USA \\ kevin.thompson@uconn.edu
}

\begin{abstract}
Instructional design models provide process insight that guides learning solution designers in their work to meet learning objectives and improve performance. Human resource development scholars often focus on individual learning components that support meeting learning and performance objectives. Learning practitioners who design learning solutions must review significant amounts of research studies to extract information that may assist them in their roles. This paper introduces the evidence-based Synergetic Learning Model, focused exclusively on design, intended to leverage the work of scholars holistically for the benefit of learning practitioners.
\end{abstract}

Keywords-Instructional design model, human resource development, adult learning, evidence-based, synergy, learning objectives, performance objectives.

\section{Introduction}

In 2018, U.S. organizations spent $\$ 87.6$ billion on the training and development of employees [21]. That figure, up $6.4 \%$ from 2017 , represents a significant investment in employee development [21]. Over the last six years the largest increase in spending has occurred in management and supervisory training, up 30\% during that time period [21]. Learning and development staff including the instructional designers who design learning solutions accounted for $\$ 47$ billion of the total investment [21]. A recent empirical study of instructional designers indicated half of the 113 surveyed used instructional design theories to design learning solutions [11]. A review of the Educational Resources Information Center (ERIC) database showed 429 articles with the word 'instructional design' in the title between 2003 and 2017 representing an average of 28 new articles per year. While half of instructional designers demonstrate interest in theory, new scholarly activity makes staying abreast of valuable literature challenging. As the amount of information available to inform instructional design strategies grows, so does the need for practical and productive instructional design (ID) models. More importantly, ID models often focus on the holistic process required to support the attainment of learning objectives leaving the actual design of the learning solution as a potentially significant scholarly contribution to the literature and the field.

A number of ID models have been authored over time by various scholars [22, 49]. Instructional design includes the analysis, design, development, implementation, evaluation (ADDIE) and management of processes focused on learning and performance 
improvement [38]. What is important is to distinguish the typical definition of instructional design with instructional design process and the design of programmatic learning solutions. Instructional design, with a process focus, is well-described by Branch and Kopcha whose definition is, "... activities associated with preparing lesson plans and determining moment-to-moment instructional strategies, sequencing motivational elements, and learner actions." (p. 78) [5]. The operative word in this definition is 'activities' which infers analysis, design, development, implementation, and evaluation (ADDIE) of programmatic learning solutions. Different from this are models that focus on design exclusively which is the primary focus of this paper.

\section{$2 \quad$ Synergetic Learning Model}

The function of the Synergetic Learning Model (SLM) is to provide instructional designers and learning and development leaders with a practical guide to designing and developing comprehensive, end-to-end learning solutions that increase and accelerate knowledge transfer. The SLM is specifically intended to remove focus from formal learning events and apply it where more learning can be supported and achieved. Baldwin and Ford define transfer of training as, "the degree to which trainees effectively apply the knowledge, skills, and attitudes gained in a training context to the job." (p. 63) [2]. An end-to-end learning solution supports learning from the onset of a learning program until stated learning and performance objectives are achieved. The origin of the SLM is heavily grounded in scholarly research that provides an evidence-based foundation for each component of the model.

\section{Model Introduction}

The operative phrase in the SLM functional description is end-to-end learning. Instructional design model literature is typically focused on supporting the development of individual learning activities like online or live learning events ([31, 34]. Beyond ID model research, scholars typically focus on a single learning factor like feedback [1, 19], reflection [26, 29, 40], or on-the-job learning [2, 27, 28, 37]. Through the SLM, I offer a comprehensive ID model that leverages scholarship from the time a learner is introduced to a learning solution [6] until they are proficient in using newly acquired knowledge to perform [19].

\section{$4 \quad$ SLM Design}

The SLM [see Figure 1] includes six components that support end-to-end learning: Engage, Prepare, Apply, Reflect, Perform, and Performance Support. Engage enables learners to become intellectually involved in, and commit to, a learning solution. Prepare exposes learners to new concepts and theories that are foundational to achieving the desired learning. Apply consists of using new concepts and theories, in a safe setting, including real-world examples. Reflect considers Engage questions and answers, 
Prepare concepts and theories, and Apply application efforts with a goal of supporting new learning and uncovering unresolved questions for resolution. Perform is the onthe-job application and use of new learning to enhance performance by improving productivity, accuracy, results, or capability. Performance Support are resources, processes, practices, tools, and staff provided to learners to help them learn and work successfully and efficiently throughout the learning process [see Table 1].

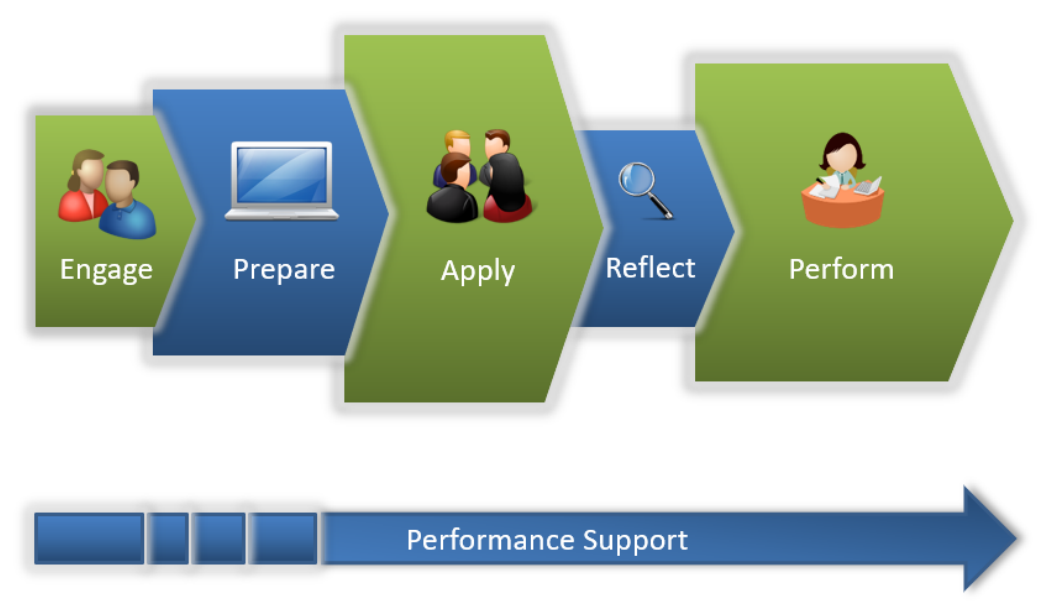

Fig. 1. Synergetic Learning Model

Table 1. Synergetic Learning Model Component Descriptions

\begin{tabular}{|c|c|}
\hline SLM Component & SLM Component Description \\
\hline Engage & $\begin{array}{l}\text { Preparing learners to become intellectually involved in a learning solution by } \\
\text { answering four key questions: What am I going to learn?; How am I going to } \\
\text { apply what I'm going to learn?; How will what I am going to learn benefit } \\
\text { me?; and, How will what I'm going to learn benefit the organization? }\end{array}$ \\
\hline Prepare & $\begin{array}{l}\text { Exposing learners to new concepts and theories that are foundational to achiev- } \\
\text { ing the desired learning outcome. This is often accomplished through pre-reads } \\
\text { or pre-work that take place prior to an Apply formal learning event. }\end{array}$ \\
\hline Apply & $\begin{array}{l}\text { Applying new concepts and theories using real-world examples, cases, and set- } \\
\text { tings. Apply can include facilitator or technology-led simulations, trial and er- } \\
\text { ror, role play, building something, writing something, reviewing, etc. Apply is } \\
\text { often a live/virtual learning event which creates a safe learning environment } \\
\text { and allows for immediate feedback. }\end{array}$ \\
\hline Reflect & $\begin{array}{l}\text { Reflecting on the Engage questions and answers, the Prepare concepts and } \\
\text { theories, and the Apply application efforts with a goal of cementing new learn- } \\
\text { ing and surfacing unresolved questions for future resolution. Learners Reflect } \\
\text { within } 24-48 \text { hours of formal learning events and is accomplished through a } \\
\text { follow-up email or call or a brief meeting focused on discussing questions and } \\
\text { gaps in learning identified by learners. }\end{array}$ \\
\hline Perform & $\begin{array}{l}\text { Participating in prescribed on-the-job use of new learning to improve perfor- } \\
\text { mance by improving productivity, accuracy, results, or capability. Prescribed, } \\
\text { planned Perform activities enhance and accelerate on-the-job learning for ex- } \\
\text { ample: periodic small group meetings to discuss what's going well and what } \\
\text { isn't, question and answer sessions, threaded discussion, observation of ex- } \\
\text { perts, best practice and success story communication, follow-up emails, etc. }\end{array}$ \\
\hline
\end{tabular}




\begin{tabular}{|l|l|}
\hline & $\begin{array}{l}\text { Any recurring Perform activity should include frequency and duration (i.e. } \\
\text { how often and how long the activity will go on). }\end{array}$ \\
\hline $\begin{array}{l}\text { Performance } \\
\text { Support }\end{array}$ & $\begin{array}{l}\text { The resources, processes, practices, and tools the organization provides its } \\
\text { learners for them to learn to perform their work successfully and efficiently. It } \\
\text { serves to answer learner's questions only as there are no activities in Perfor- } \\
\text { mance Support. In addition to coaches, mentors, and managers virtually any- } \\
\text { thing that can reside in a digital media repository has Performance Support po- } \\
\text { tential. }\end{array}$ \\
\hline
\end{tabular}

\subsection{Engage}

The initiating SLM component is Engage and is intended to provide learners with the opportunity to understand what is to be learned and why. This component is underpinned by the precept that emotion is the precursor to learning [25]. Recognizing and responding to complex situations, like learning opportunities, requires emotional processing [25]. Engage must provide enough information to render an emotional response, hopefully positive, related to the learning opportunity. Once engaged, learners have the ability to become involved and direct involvement energy, both psychological and physical, toward learning [15].

The information provided in Engage to generate an emotional response is also used by the learner to make a self-efficacy judgment. Bandura defines self-efficacy as "...judgments of how well one can execute courses of action required to deal with prospective situations." (p.122) [3]. When applied to a learning opportunity, self-efficacy is the learner's belief in whether they can successfully accomplish the requested learning and related performance. When self-efficacy is high, learners will persist through learning and performance activities by overcoming adverse experiences and obstacles [3]. Engage must provide sufficient information to encourage learner self-efficacy.

Achieving Engage information goals is based on the work of Brinkerhoff and Apking who suggest preparing learners to become emotionally and intellectually involved in a learning solution by answering four key questions:

1) What am I going to learn?

2) How am I going to apply what I'm going to learn?

3) How will what I am going to learn benefit me?

4) How will what I'm going to learn benefit the organization? (p. 9) [6]

Questions one and two represent the foundation upon which the learner's self-efficacy judgment is made. By understanding what they are going to learn and how they will use new knowledge (Perform), the learner can determine their level of confidence in whether they can attain desired outcomes. Understanding what is going to be learned and how it will be applied aligns with Speicher, Kehrhahn, Bell, and Casa's [41] study of novice learners and the perception of applicability. The authors found that when novice learners were unsure about how to apply new information, they often focused on superficial aspects of what they were learning instead of grasping similarities with existing practice. Adding cues (prompting or provision of hints) regarding application during the learning process increased knowledge transfer for novice learners [41]. Cues, 
in the form of answers to Engage questions, allow learners to understand the applicability of what they are learning such that they invest time accordingly.

Questions three and four provide the information that elicits an emotional response to the desired learning and performance goals. In essence, these two questions provide 'what's in it for me and my organization' insight which can create an emotional response. For example, happiness may result if there is potential for a raise or greater organizational success that may increase bonuses. Alignment of the emotional response with learning and performance goals allows learners to recognize and respond appropriately to learning challenges. When the four questions are answered by learners, knowledge transfer increases 16\% [7]. The answers to the Engage questions may occur through a program launch conference call or webinar for all participants or groups of participants, or through brief meetings between participant and trainer or participant and manager. Multiple exposures to Engage question answers are likely to produce deeper understanding and engagement.

\subsection{Prepare}

Prepare is the second SLM component. It exposes learners to new concepts and theories that are foundational to achieving the desired learning outcome. Zull [50] pinpoints four pillars of learning: gathering data, creating, testing, and reflection. While SLM phases are supported by each of the four pillars, gathering data through information provided in the learning program is specifically aligned with Prepare. Gathering data is the process of getting information that initiates the brain's learning process [48]. Prepare provides the information sources in which the ideas for abstract conceptualization are found. Abstract conceptualization, one of Kolb's [30] adaptive learning modes, is when learners analyze ideas and create explanative theories.

Choo [10] identifies eight key information-seeking behaviors, five of which inform Prepare: chaining, browsing, differentiating, verifying, and extracting. Chaining is piecing together information sources through cross-referencing, and browsing involves cursory, high-level information source reviews [10]. Differentiating is selecting information from a variety of sources, and verifying ensures information sources are accurate. Extracting behavior is the systematic consideration of information sources to identify material of interest [10]. The five information-seeking behaviors are supported in Prepare through the purposeful provision of a variety of information sources that align with learning objectives.

Prepare, then is a compilation of information sources provided by learning designers to learners for introductory review. The information sources vary in format and can include written references, podcasts, job-aids, videos, and simulations. The designer of the learning solution selects the information sources that support the learner to acquire new knowledge and attain learning objectives.

During Prepare those learning to be building inspectors may review hundreds of pages of building codes designed to ensure long-term building quality and safety. People developing negotiating skills may review podcasts that convey negotiating principles and successful and unsuccessful application. When learning to use a new computer system, participants may receive a job-aid that summarizes system use and they may 
view a simulation that shows the system in use executing typical tasks. Videos are a Prepare format that allows learners to see and hear new information. Review of Prepare reference materials is completed prior to initiating the SLM Apply component.

\subsection{Apply}

Apply is the third SLM phase and is the first opportunity for learners to use the information from Prepare experientially. Apply is a gathering of learners, typically a 'live' event that is held in-person or virtually for the purpose of experiencing the use of new information as learners might on the job. Apply is based on the premise that, "Knowledge is continuously derived from and tested out in the experience of the learner." (p. 27) [30]. Kolb [30] describes learning as the process of creating knowledge through the transformation of experience. The key to a successful Apply phase is to provide learners with experiences that resemble how they will use new information in the workplace in a designed effort to create knowledge and learn. Providing feedback throughout the Apply phase enhances learning outcomes.

Feedback is characterized as "informed, nonevaluative, objective appraisal of performance intended to improve skills" (p. 779) [18]. The provision of timely feedback is known to enhance learning [1]. Within the SLM, feedback is incorporated in multiple model components (Apply, Reflect, Perform) to enhance learning and performance outcomes.

Apply experiences use real-world examples, cases, and settings and range from role plays to simulations to small group discussions and debrief sessions with other participants. Apply is facilitated by trainers and/or subject matter experts who guide participants through the prescribed Apply activities as well as provide performance feedback in real-time. Learners participate in practice that looks like what they will see when asked to apply new knowledge in their roles. Trial and error and feedback fuel the creation of new knowledge. As the learning process unfolds and gains momentum, learning is enhanced with key experiences that are multi-dimensional [42], challenging [19], and complex [20]. When key experiences are combined with deliberate practice [20] and feedback [1] the development of new knowledge improves.

Apply experiences are as varied as the material to be learned. A group of learners focused on using a new computer system can spend hours executing tasks using the new system to produce desired results. Those gathered to build negotiating skills partner with other learners to practice negotiating win-win outcomes based on a set of goals and desired outcomes. Developing diagnostic skills related to new diseases and treatment options requires physicians to practice asking questions of patient stand-ins with simulated symptoms. Providing building inspectors with the knowledge they need to perform their role is assisted by responding to code and non-code examples of building situations they will face on the job. Problem-based learning is another potential Apply activity. Within problem-based learning, new knowledge is derived as an ambiguous and complex problem is resolved by learners [47]. Each of these examples is focused on applying concept and theory in real-life scenarios.

Apply not only provides real-life experience it offers the opportunity to provide immediate feedback and answer questions. Immediate response corrects application errors 
before they become embedded and derail achieving learning objectives. If the learner cannot use a new computer system to achieve desired results, immediate feedback shows the learner how to be successful $[1,14,18]$. If a doctor misses asking a key diagnostic question that error is pointed out immediately. By observing others in a simulated negotiation session, best practices arise and are identified. For building inspectors, failure to accurately identify construction deficiencies is captured and rectified in real time.

Gathering students during Apply leverages the value of small groups and learning. A recent meta-analysis of knowledge transfer in small groups as compared to individual learning resulted in a 30\% increase in knowledge transfer in small groups [35]. Some of the empirical research articles used in the meta-analysis showed knowledge transfer increases of up to $100 \%$ in small groups [35]. Meta-analysis authors described small groups as students working together to achieve shared learning objectives [35]. The researchers found no difference in transfer between structured and unstructured small groups [35] as people observe, imitate, model, and question the successful behavior of others.

The group construct of Apply provides the opportunity for social learning as learners see others applying new knowledge and practice themselves [16]. Mistakes are seen and remediation is understood as fellow learners engage in application exercises. Trial and error outcomes are experienced first and second hand which improves learning efficiency for all participants. Best practices arise and are noted by learning facilitators. The unique previous experiences of participants are shared through application such that all participants benefit from the expertise and experience of others.

By gaining experience in practice, learners begin the process of learning which in turn supports the attainment of learning and performance objectives. Upon completion of the Apply SLM component, learners still have gaps in knowledge that will prevent them from maximizing job performance. The ability to reflect on the Apply experiences allows gaps to surface through questions from learners.

\subsection{Reflect}

Reflection has long been known as a method for enhancing learning and learning outcomes as it connects disciplinary concepts and concrete experiences [12, 33, 40]. Reflection supports the integration of new with existing knowledge and helps learners to be self-aware and engage in metacognition [12]. Reflective practice can be focused on thinking through intentions, values, beliefs, and feelings [33], and exploring what provoked actions or what was happening. The goal of reflection is to develop a set of questions and ideas about our activities and practice. The SLM Reflect component prescribes a reflective activity within 24-48 hours of the Apply component and aligns with the spaced repetition concept. While there is much value in planning reflective activities throughout the SLM, there is particular value in having Reflect follow Apply as that is the steepest (negative) slope of the forgetting curve [17].

The Reflect component asks learners to employ a cognitive process to increase understanding of the learning experiences [8] that occurred in Engage, Prepare, and Apply towards a goal of identifying unanswered questions which arise from the failure to 
make desired neuronal connections. Examples of Reflect activities include debriefs at the close of Apply, follow-up emails, follow-up group discussion, and discussion with managers.

Debriefs at the close of Apply can ask learners to reflect on the time spent together and articulate key takeaways so that all participants become aware of the important learnings from each learner. Debriefs can also raise issues regarding what questions remain from the shared time together, what isn't understood, and what requires more clarity. The answers to these questions support building and maintaining the neuronal connections associated with learning which helps to increase new knowledge retention.

Follow-up emails can be used to solicit learner questions or ask learners to engage in a scenario that utilizes the skills that were practiced in Apply. Questions asked could be: do you have any unanswered questions from our recent time together, or what material have we covered that you don't understand? An e-mail application scenario can be quite similar to those used in Apply, such that participants apply new knowledge and instructors have the opportunity to provide feedback. Providing answers to questions or feedback to application scenarios are opportunities to support learning.

Group discussions that follow Apply sessions provide the opportunity to ask and answer questions, articulate key learnings, and use new knowledge in a simulated experience. Directly following Apply sessions serves to mitigate forgetting and meeting in groups supports sharing unique new knowledge perspectives. Group discussions provide an opportunity to engage in new material again and leverage the different experiences of the learners.

Discussion with managers provides the context for a one-on-one coaching session regarding what is being learned and how it is applied at work. Manager discussion is a perfect time to review the four questions posed in Engage and determine what gaps in achieving learning objectives remain. Discussions guide the learner on what learning should be prioritized during the balance of the learning program to ensure learning objectives are accomplished and performance improvement expectations met. The manager and the organization are the recipients of the increased performance from learning such that the manager's perspective on learning success and gaps is critical information the learner can use.

Maximizing Reflect value requires immediate feedback to learner questions to support the creation or solidification of neuronal connections that increase learning. Engaging with learners, responding to questions, and providing feedback within 24-48 hours of Apply, provides a significant opportunity to mitigate forgetting and serves as a transition to new information use on the job.

\subsection{Perform}

Based on the significant negative slope of the forgetting curve, and even with correct execution of Reflect, most learning occurs outside of SLM Engage, Prepare, Apply, and Reflect components. To effectively articulate this inevitable outcome to practitioners, Lombardo and Eichinger [32] coined the phrase 70:20:10 where 70\% of learning occurs on the job, $20 \%$ from interacting with others, and $10 \%$ from learning activities. 
The 70:20:10 notion aligns with forgetting curve outcomes and is relatively easily understood by practitioners. Perform then is explicitly focused on the time period following execution of the first four SLM model components when learners are able to use the new knowledge they have acquired thus far in the workplace.

Instructional designers have the opportunity to plan spaced repetition as learning support activities to enhance and accelerate learning outcomes on the job. These prescribed activities vary based on what is being learned and what performance is expected. Perform learning supports can include job-shadowing, mentor relationships, mini-simulations, periodic small group meetings, threaded discussion, and success story communication.

Job shadowing has been found to be an effective learning support as it helps learners connect concept, theory, and classroom activities in real world context. [46]. Observing others perform work you are expected to perform helps deepen knowledge as new information is seen in use. Consider the value in having a new call center representative observe experienced colleagues meet caller needs.

Mentors are an expert source of feedback and help learners identify strengths and weaknesses in their understanding of new information. [9]. Mentors address specific behaviors and provide feedback focused on improving performance [9]. Mentors are selected based on their expertise, communication skills, and their ability to demonstrate sincere interest in the learner's success [43]. Mentor relationships are typically in place until performance objectives that drive the learning program are met.

Mini-simulations are tasks that provide learners with repeated opportunities to deliberately practice the application of new knowledge [36]. From reading and responding to a work scenario email to performing computer-based tasks in an online tutorial, simulations renew learners' consideration of new information and provide the opportunity to apply it in controlled settings. The provision of feedback in response to executing mini-simulations generates additional learning value.

Given the significant value of small groups in learning as discussed previously, it is appropriate to schedule periodic small group meetings of learners during Perform. Meetings are flexible but typically include learner questions, challenges in implementing new knowledge, success and failure stories, and considerable feedback. Often a subject matter expert attends to facilitate and enhance discussion. Learner collaboration works through challenges and dissects successes, both of which deepen learning and mitigate forgetting curve impact. Learning from the failures of others can be quite valuable as learners avoid similar future errors and the unfortunate outcomes associated with them [4].

Threaded discussion represents a continuing technology-supported, virtual small group meeting. Threaded discussion can include a variety of topics under concurrent consideration [13]. There is typically an initial post followed by additional posts captured as a discussion [13]. Learners request information from others and receive intellectual and academic support [13]. Learners reflect on the experiences of others and articulate their own challenges and successes. Responses to postings are an additional source of expertise. Threaded discussion is typically moderated by an expert who can provide appropriate information and feedback as well as correct inaccuracies. 
Communicating success stories, in this case the successful application of new knowledge, serves three purposes: repeats interaction with new information, offers examples of how new information can be applied to meet performance objectives, and improves self-efficacy. Each success story conveyance represents another spaced repetition which mitigates forgetting curve outcomes [17]. Successful examples of new information application support abstract conceptualization when learners analyze ideas (successes) and consider outcomes [30]. When learners see other learners successfully apply new information, there is a likely positive impact on self-efficacy [3]. Success story communication can occur in many formats, including emails, websites, meetings, podcasts, and videos. While all of the aforementioned examples are appropriate Perform components, any learning support activity that can be planned and prescribed for learners to reconsider or apply new information is worthy of inclusion.

Throughout Perform there is significant value in prescribing debrief activities that review work for correct performance. Debriefing is an iterative process of reflection and planning to improve future performance [43]. Both individual and teams can perform debriefs. A team debrief reviews recent work activity accomplished by a group of workers who consider recent performance and related performance improvement. When team debriefs are facilitated by experts, they are about three times as effective as non-facilitated debriefs [43]. Individual debriefing has value similar to team debriefs to enhance individual learning and performance improvement when debriefs occur in concert with experts [43].

\subsection{Performance Support}

Performance Support are the resources, processes, practices, and tools the organization provides its learners for them to learn and perform their work successfully and efficiently over time $[23,24,39]$. In addition to subject matter experts, coaches, mentors, and managers, virtually anything that can reside in a searchable digital media repository (DMR) has Performance Support applicability. The DMR (e.g. Wikipage or organization Intranet site) can store all Performance Support references.

Building the DMR begins with the Engage questions and answers and continues with the addition of all Prepare materials. Each Apply activity and all Reflect questions and answers are also added. Any references provided or captured in Perform are placed in the DMR along with mini-simulations, small group meeting minutes, threaded discussions, and success stories. Any other reference that might be useful to learners to meet learning and performance objectives, like job aids, podcasts, videos, and articles, are also included. The result is a robust, searchable collection of reference materials available to learners whenever needed.

Learning guides are subject matter experts, coaches, mentors, and managers with the knowledge, competence, and availability to answer questions or provide resources that support learning [44]. It's valuable to consider that millennials in the workplace expect learning guides to be sincerely interested in their success [44]. Like subject matter experts, coaches, mentors, and managers, each learning guide assigned to support learners should be listed in the DMR including contact information and areas of expertise. The 
goal of learning guide DMR inclusion is easy access to live support. Learners understand that learning guides are not available all the time and will rely on other DMR references as needed.

Performance Support is made available to learners from the onset of the learning solution (i.e. Engage) until performance objectives are met (i.e. Perform). A key Performance Support objective is to provide answers to questions and as such, reduce the impact of the forgetting curve. Another is to provide guidance when applying new information on the job. Therefore, Performance Support must be readily accessible and easily searched.

\section{$5 \quad$ Limitations}

The SLM as described supports learning opportunities that are designed, structured, linear, on a schedule, and in group settings. In addition, SLM outcomes benefit from the support of key organizational staff including SMEs, mentors, and learning guides that provide insight, feedback, and sincere interest in learner success. These conditions are not always reflective of organizational learning where on-the-job, just-in-time, ashired, and other individual and independent learning is common.

\section{Discussion}

The SLM provides instructional designers with evidence-based guidance to improve the design of learning solutions. The model's focus on design adds to the value of preexisting ID models $[22,49]$ that are more process than design oriented. As opposed to other ID models that include needs identification, analysis, and prioritization; design; delivery; and evaluation; the SLM and its design centricity exploits a significant opportunity to improve learning solution outcomes. Since each SLM component is rooted in empirical research, adding any component to a learning solution design increases value. Combining all components supports synergy development resulting in the sum being greater than the individual parts.

Underscoring the model with Performance Support creates an anchoring effect similar to a structural foundation. SLM accessibility relates to the simplicity of the model and the ease with which each component of the model is explained and exemplified. In a short period of time novices and skilled instructional designers absorb the model's intent. Understanding the model includes not only comprehending the intent and value of each SLM component but also grasping the synergetic nature of using all components when designing learning solutions. As for ease of application, the components as described are not difficult to design into learning solutions. The examples for each SLM component offer instructional designers initial application guidance and spark creating additional choices.

Impetus for developing the SLM was the continuing focus on formal learning events including classroom and online variants which results in minimal long-term knowledge transfer [17]. The unfortunate formal learning event focus is exacerbated by measuring training based on how many hours employees receive annually [21]. Since the SLM 
deemphasizes formal learning events and applies it where more learning can be supported and achieved the size of each component, as depicted on the model graphic, spreads attention, effort, and application across a wider learning continuum. Through both graphical presentation and informative discourse, the SLM guides learning and performance improvement practitioners to improve learning solution design with evidence-based input.

\section{Conclusion}

Adult learning and HRD literature is replete with evidence-based suggestions regarding how to improve learning and performance outcomes. The SLM assists practitioners in the development of more effective learning and development programs. While significant empirical evidence exists for each SLM phase, SLM structure provides for the addition of other evidence-based learning supports. For example, other proven methods of supporting on-the-job learning can be added to Perform. The Synergetic Learning Model represents an evidenced-based ID model focused on combining a multiplicity of scholarly research efforts to synergistically improve learning and performance outcomes.

\section{$8 \quad$ References}

[1] Bakken, L. (2002). Role of experience and context in learning to diagnose lyme disease. The Journal of Continuing Education in the Health Professions, 22, 131-141. https://doi.org/10.1002/chp.1340220302

[2] Baldwin, T. T., \& Ford, J. K. (1988). Transfer of training: A review and directions for future research. Personnel Psychology, 41(1), 63-105. https://doi.org/10.1111/j.1744$\underline{6570.1988 . t b 00632 . x}$

[3] Bandura, A. (1982). Self-efficacy mechanism in human agency. American Psychologist, 39(2), 122-147. https://doi.org/10.1037/0003-066x.37.2.122

[4] Bledow, R., Carette, B., Kühnel, J., \& Bister, D. (2017). Learning from others' failures: The effectiveness of failure stories for managerial learning. Academy of Management Learning \& Education, 16(1), 39-53. https://doi.org/10.5465/amle.2014.0169

[5] Branch, R. M., \& Kopcha, T. J. (2014). Instructional design models. Handbook of research on educational communications and technology (pp. 77-87) Springer New York. https://doi.org/10.1007/978-1-4614-3185-5 7

[6] Brinkerhoff, R. O., \& Apking, A. M. (2001). High impact learning (First ed.). Cambridge MA: Basic Books.

[7] Brinkerhoff, R. O., \& Montesino, M. U. (1995). Partnerships for training transfer: Lessons from a corporate study. Human Resource Development Quarterly, 6(3), 263-74. https://doi.org/10.1002/hrdq.3920060305

[8] Cajiao, J., \& Burke, M. J. (2016). How instructional methods influence skill development in management education. Academy of Management Learning \& Education, 15(3), 508-524. https://doi.org/10.5465/amle.2013.0354

[9] Chien, C. (2015). Pre-service English teachers' perceptions and practice of field experience and professional learning from expert teachers' mentoring. Teachers and Teaching: Theory and Practice, 21(3), 328-345. https://doi.org/10.1080/13540602.2014.953817 
[10] Choo, C. W. (2005). The knowing organization: How organizations use information to construct meaning, create knowledge, and make decisions. Oxford: Oxford University Press. https://doi.org/10.1108/ccij.1999.4.2.106.2

[11] Christensen, T., \& Osguthorpe, R. (2004). How do instructional-design practitioners make instructional-strategy decisions? Performance Improvement Quarterly, 17(3), 45-65. https://doi.org/10.1111/j.1937-8327.2004.tb00313.x

[12] Coll, R. K., Eames, C., Paku, L., Lay, M., Hodges, D., Bhatt, R., Martin, A. (2009). An exploration of the pedagogies employed to integrate knowledge in work-integrated learning. The Journal of Cooperative Education and Internships,

[13] Cox, B., \& Cox, B. (2008). Developing interpersonal and group dynamics through asynchronous threaded discussions: The use of discussion board in collaborative learning. Education, 128(4), 553-565.

[14] Cyboran, V. (1995). Designing Feedback for Computer-Based Training, 34, 18-23.

[15] Dean, K., \& Jolly, J. (2012). Student identity, disengagement, and learning. Academy of Management Learning \& Education, 11(2), 228. https://doi.org/10.5465/amle.2009.0081

[16] Deaton, S. (2015). Social learning theory in the age of social media: Implications for educational practitioners. Journal of Educational Technology, 12(1), 1-6.

[17] Ebbinghaus, H. (1885). Über das gedächtnis: Untersuchungen zur experimentellen psychologie Books on Demand.

[18] Ende, J. (1983). Feedback in clinical medical education. JAMA: Journal of the American Medical Association, 250(6), 777-781. https://doi.org/10.1001/jama.250.6.777

[19] Enos, M. D., Kehrhahn, M. T., \& Bell, A. (2003). Informal learning and the transfer of learning: How managers develop proficiency. Human Resource Development Quarterly, 14(4), 369-397. https://doi.org/10.1002/hrdq.1074

[20] Ericsson, K. A., \& Charness, N. (1997). Cognitive and developmental factors in expert performance. In P. J. Feltovich, K. M. Ford \& R. R. Hoffman (Eds.), Expertise in context: Human and machine (pp. 3-4-41). Cambridge, MA: The MIT Press. https://doi.org/10.1017/ cbo9780511816796.004

[21] Freifeld, L. (2018). 2018 training industry report. Excelsior MN. Training Magazine. Retrieved from https://trainingmag.com/trgmag-article/2018-training-industry-report/

[22] Gagne, R., Briggs, L., \& Wagner, W. (1992). Principles of instructional design. Fort Worth: Harcourt Brace Javonovich.

[23] Gottfredson, C., \& Mosher, B. (2011). Innovative performance support. New York, NY: McGraw-Hill

[24] Hochwarter, W. A., Witt, L. A., Treadway, D. C., \& Ferris, G. R. (2006). The interaction of social skill and organizational support on job performance. Journal of Applied Psychology, 91(2), 482-489. https://doi.org/10.1037/0021-9010.91.2.482

[25] Immordino-Yang, M., \& Damasio, A. (2007). We feel, therefore we learn: The relevance of affective and social neuroscience to education. Mind, Brain, and Education, 1(1), 3-10. https://doi.org/10.1111/j.1751-228x.2007.00004.x

[26] Jackson, D. (2015). Employability skill development in work-integrated learning: Barriers and best practice. Studies in Higher Education, 40(2), 350-367. https://doi.org/10.1080/ 03075079.2013 .842221

[27] Jacobs, R. L., \& Bu-Rahmah, M. (2012). Developing employee expertise through structured on-the-job training (S-OJT): An introduction to this training approach and the KNPC experience. Industrial \& Commercial Training, 44(2), 75-84. https://doi.org/10.1108 $\underline{100197851211202902}$ 
[28] Johnson, S. D., \& Leach, J. A. (2001). Using expert employees to train on the job. Advances in Developing Human Resources, 3(4), 425-434. https://doi.org/10.117 7/15234220122238481

[29] Jonker, L., Elferink-Gemser, M., de Roos, I. M., \& Visscher, C. (2012). The role of reflection in sport expertise. The Sport Psychologist, 26(2), 224-242. https://doi.org/10. $\underline{1123 / \text { tsp.26.2.224 }}$

[30] Kolb, D. A. (1984). Experiential learning: Experience as the source of learning and development. Englewood Cliffs, N.J.: Englewood Cliffs, N.J.: Prentice-Hall.

[31] Lee, J., \& Jang, S. (2014). A methodological framework for instructional design model development: Critical dimensions and synthesized procedures. Educational Technology Research and Development, 62(6), 743-765. https://doi.org/10.1007/s11423-014-9352-7

[32] Lombardo, M., \& Eichinger, R. (2010). Career architect development planner (5th ed.). Minneapolis, MN: Lominger International.

[33] Mezirow, J. (1997). Transformative learning: Theory to practice. New Directions for Adult and Continuing Education, 1997(74), 5-12. https://doi.org/10.1002/ace.7401

[34] Murphy, K. L., \& Holme, T. A. (2014). Improving instructional design with better analysis of assessment data. Journal of Learning Design, 7(2), 28-46. https://doi.org/10.5 204/jld.v7i2.199

[35] Pai, H., Sears, D. A., \& Maeda, Y. (2015). Effects of small-group learning on transfer: A meta-analysis. Educational Psychology Review, 27(1), 79-102. https://doi.org/10.10 07/s10648-014-9260-8

[36] Pankowski, J., \& Walker, J. T. (2016). Using simulation to support novice teachers' classroom management skills: Comparing traditional and alternative certification groups. Journal of the National Association for Alternative Certification, 11(1), 3-20.

[37] Pappa, D., Faltin, N., \& Zimmermann, V. (2009). Applying business process oriented learning in industry: The PROLIX solution approach based on a case study. International Journal of Advanced Corporate Learning, 2(1), 16-24. https://doi.org/10.3991/ijac.v2i1.803

[38] Reiser, R. A. (2001). A history of instructional design and technology: Part I: A history of instructional media. Educational Technology Research and Development, 49(1), 53-64. https://doi.org/10.1007/bf02504506

[39] Rhoades, L., \& Eisenberger, R. (2002). Perceived organizational support: A review of the literature. Journal of Applied Psychology, 87(4), 698-714. https://doi.org/10.1037/0021$\underline{9010.87 .4 .698}$

[40] Schön, D. A. (1989). Quotations. A symposium on schon's concept of reflective practice: Critiques, commentaries, illustrations. Journal of Curriculum and Supervision, 5(1), 6-9.

[41] Speicher, T. E., Bell, A., Kehrhahn, M. T., \& Casa, D. J. (2012). Case-based analogical reasoning: A pedagogical tool for promotion of clinical reasoning. Athletic Training Educational Journal, 7(3), 129-136.

[42] Stark, R., Renkl, A., Gruber, H., \& Mandl, H. (1998). Indeed, sometimes knowledge does not help: A replication study. Instructional Science, 26(5), 391-407. https://doi.org/10.10 23/a:1003209514232

[43] Tannenbaum, S. I., \& Cerasoli, C. P. (2013). Do team and individual debriefs enhance performance? A meta-analysis. Human Factors: The Journal of Human Factors and Ergonomics Society, 55(1), 231-245. https://doi.org/10.1177/0018720812448394

[44] Thompson, K. S. (2016). Organizational learning support preferences of millennials. New Horizons in Adult Education and Human Resource Development, 28(4), 15-27. https://doi.org/10.1002/nha3.20158

[45] Training Industry. (2018). Formal learning. Retrieved from https://trainingindustry.com/glossary/formal-learning/ 
[46] Trapp, S., Thomas, L., \& Möbs, S. (2009). Tailoring technology-enhanced learning arrangements to individual needs. International Journal of Advanced Corporate Learning, 2(2), 4045. https://doi.org/10.3991/ijac.v2i2.833

[47] Ungaretti, T., Thompson, K. R., Miller, A., \& Peterson, T. O. (2015). Problem-based learning: Lessons from medical education and challenges for management education. Academy of Management Learning \& Education, 14(2), 173-186. https://doi.org/10.54 65/amle.2013.0245

[48] Wilks, J., \& Ross, K. (2014). Shadowing, "the most valuable thing you can do": Threading informal classroom experiences into secondary pre-service teacher education. Teacher Education Quarterly, 41(2), 93-106.

[49] Willis, J. (1995). A recursive, reflective instructional design model based on constructivistinterpretivist theory. Educational Technology, 35(6), 5-23.

[50] Zull, J. E. (2006). Key aspects of how the brain learns. New Directions for Adult and Continuing Education, (110), 3-9. https://doi.org/10.1002/ace.213

\section{Author}

Kevin Thompson is an Assistant Professor in Residence of Management at the University of Connecticut, USA. The Management Department is located at 2100 Hillside Rd, Storrs, CT 06268. He teaches human capital courses in the Human Resources Management graduate program and at the undergraduate level, as well as the strategy capstone course for undergraduate business students. Kevin advises honors students on experiential honors projects, is a service-learning fellow leading experiential, servicelearning projects for the School of Business, and is a member of the Academy of Human Resource Development.

Article submitted 2019-11-07. Resubmitted 2020-01-15. Final acceptance 2020-02-07. Final version published as submitted by the authors. 